\title{
The first academic home for the dental team is born
}
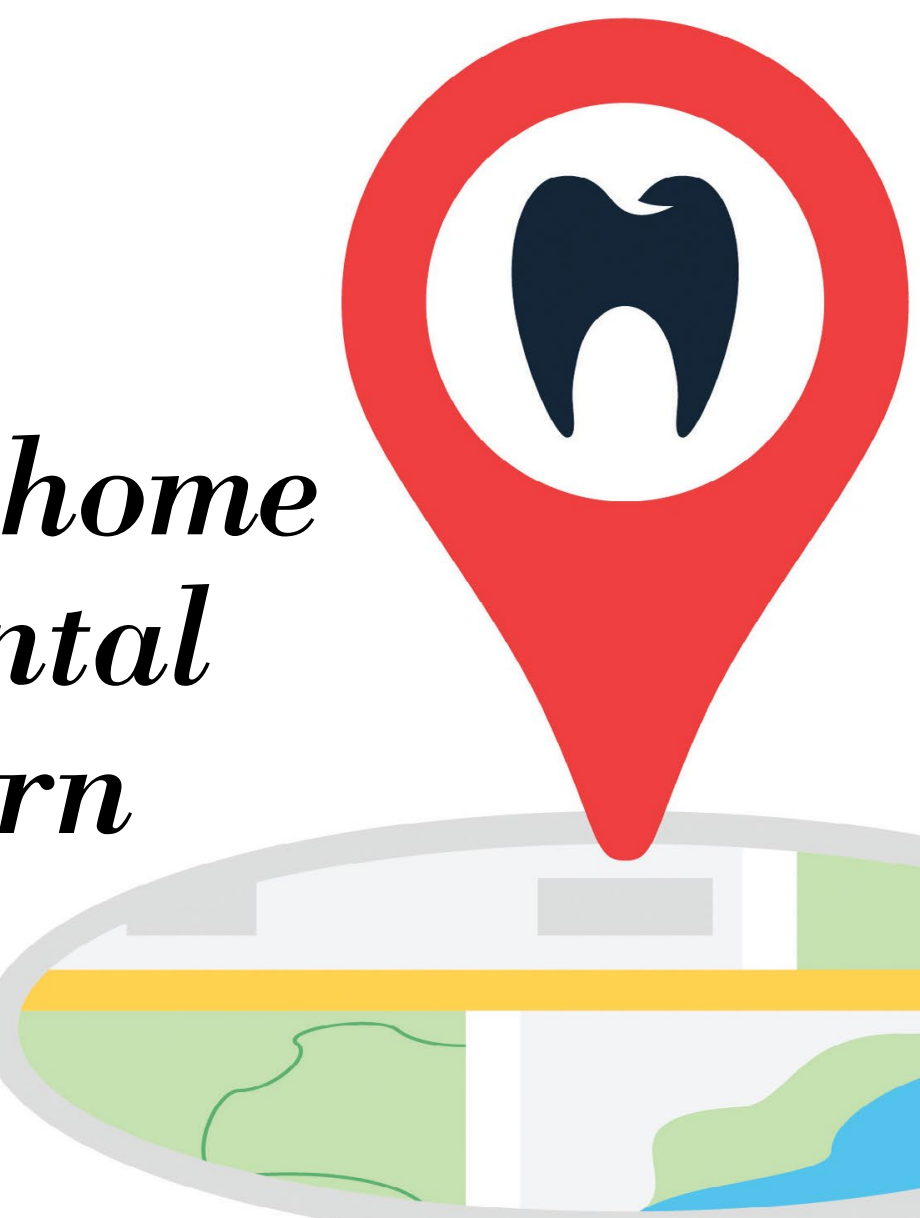

\section{The new College of General Dentistry will allow dental team members to stand shoulder to shoulder with dentists within a shared professional home. Caroline Holland speaks to dental care professionals (DCPs) who explain what the new College will offer.}

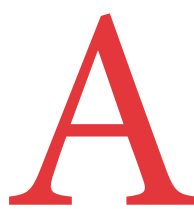

College open to the entire dental team is such an essential step that dental professionals of the future may look back and wonder why it took so long. This wry reflection is from dental technologist Steve Taylor, one of many DCP opinion leaders looking forward keenly to 1 July 2021 when the College of General Dentistry comes into being.

'For me, as a dental technician for nearly 40 years, it felt that we were on our own. I want the voice of technicians to be recognised and I want to play a part at any level I can. I believe a College for the entire dental team will improve communication and respect across dentistry.'

A Board member of the Dental Laboratories Association and Chairman of the British Institute of Dental and Surgical Technologists, Steve became an associate member of the College of General Dentistry
- or CGDent as it is familiarly known - as soon as it was possible.

'As technicians we are such a small part of the profession that our own qualifications are not necessarily recognised. A postnominal with CGDent included will bring valuable recognition.'

Postnominals are qualification acronyms and, once CGDent qualifications with associated postnominals are created, they will demonstrate competence to the profession and public alike, Steve believes.

He is one of more than 700 individual supporters already named on the CGDent website while more than 60 organisations across healthcare and dentistry have pledged support. This year, two DCPs have been named as College Ambassadors: Dr Marina Harris, a former president of the British Society of Dental Hygiene and Therapy and Dr Louise Belfield, dental nurse, research scientist and a trustee of the National Examining Board for Dental Nurses.
Meanwhile, individual DCPs have joined the College as associate members and also been invited onto some of the all important working groups, helping to carve out career pathways and qualifications.

Among them is dental technician Andrea Johnson, Chair of the charity Den-Tech, who is on the CGDent Reference Group for career pathways and the Advisory Strategy Group. When she was first approached by the College trustees, she was immediately reassured by their commitment to the team concept; she became involved in an intense programme of work to create a career pathway for technicians followed by development of the validation process.

'They have been so receptive to all our feedback. There is no other association in the UK which caters for dental team as equals. This is exactly what they are striving for and I believe they will ultimately achieve: integration of everyone in the team, not dentists, with team members bolted on.' 


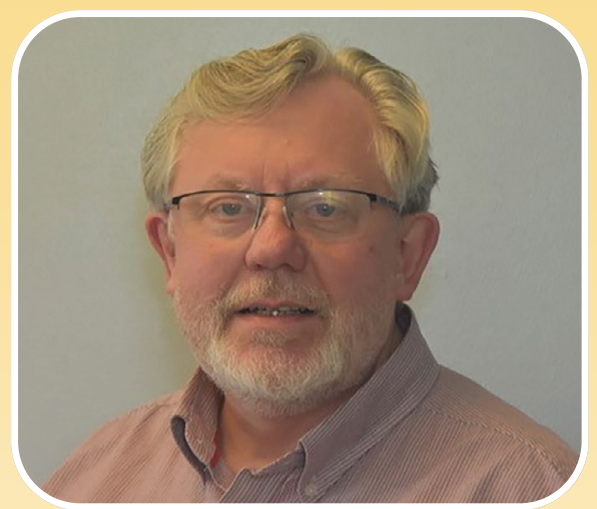

Steve Taylor

While the College of General Dentistry is already accepting members it only formally comes into being when the Faculty of General Dental Practice (FGDP) decouples from the Royal College of Surgeons at the end of June.

FGDP will be officially wound up but its assets, including its highly valued Standards and some of its Diploma programmes, will be transferred to the College. The formation of four faculties within the new College, one for dentists, another for hygienists and therapists, a third for dental nurses and orthodontic therapists and the fourth for dental and clinical dental technicians, signifies its commitment to career pathways and postgraduate education for all. No faculty will predominate over any other.

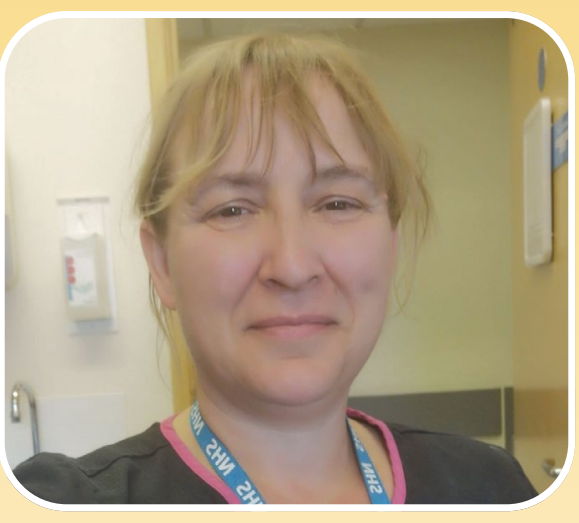

Andrea Johnson

any books out of the library. It felt like an oldfashioned approach to dentistry.'

That approach is being phased out and replaced by a more progressive view as the input of all the DCP associations are taken on board by the College trustees.

Fiona Ellwood, founder of the Society of British Dental Nurses (SBDN), is already an Honorary Fellow of the Faculty of General Dental Practice. She said it was key that ultimately all College members would be able to have the same access to research papers. 'It's my aspiration that the College should be inclusive and provide an academic home with equal opportunities for all.'

The current Chair of SBDN, Emma Riley, commented: 'The inclusivity that the College

\section{'There is a real need for a body which} is inclusive of everyone in dentistry. I

\section{wonder if we will be asking ourselves}

\section{why we didn't do this 20 years ago?'}

This is a significant change given that today the National Board of FGDP is all dentists and there is one DCP who is an observer to the board, Sarah Hill. ${ }^{1}$

DCPs could have joined FGDP but the benefits of membership were limited due to their non-dentist status. Those barriers are due to fall away. This is good news to Jacqui Elsden, President of BADN who believes that there will be valuable opportunities for dental nurses who want to pursue academic studies.

She recalls: 'When I was doing my Masters, the Faculty had resources I could use but because I was a dental nurse, I could not take of General Dentistry aims to evolve will in my eyes further enhance the opportunity for us all as members of the dental team to achieve our common goal. I myself am honoured and proud to be an early member of this College and look forward to seeing it evolve'.

Debbie Hemington, Chair of the British Association of Dental Therapists, said: 'We are very encouraged by the proposed career pathways for dental therapists and dental hygienists, and particularly the establishment of their own faculty within the College. The College have committed to complement the work of professional bodies like BADT and

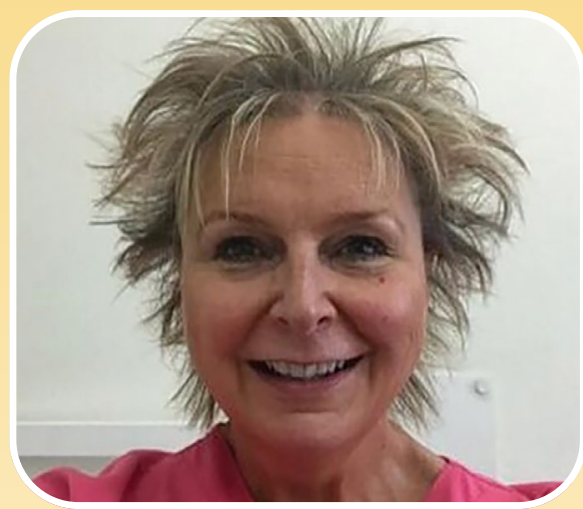

Debbie Hemington

their ethos of "we are stronger together" resonates well with us.

'Recognition of postgraduate qualifications by the College is a huge step forward for dental therapists and dental hygienists and finally acknowledges them officially as vital members of the dental team who pursue personal development and improvement as a matter of course.'

The British Society of Dental Hygiene and Therapy (BSDHT) is represented by Simone Ruzario on the Advisory Strategy Group, Miranda Steeples, their President Elect and Sarah Murray, their Hon Secretary, who are involved on working groups.

Current BSDHT President Diane Rochford said: 'There are many very experienced dental hygienists and dental therapists who could benefit from joining the college in the hope that there will be opportunities to progress their career within the proposed faculty'.

Alongside the enthusiasm and excitement, there is a pragmatic acceptance by all the DCP groups that they will have to be patient. The College owes its existence to dentists and academics and it will take time to level the playing field. But there is huge trust that the founding trustees are doing their very best to hit the ground running on 1 July.

Back to Steve Taylor: 'There is a real need for a body which is inclusive of everyone in dentistry. It seems a radical thing to be happening. I wonder if we will be looking back and asking ourselves why we didn't do this 20 years ago? But it's happening now and that's what counts'.

\section{Reference}

1. Quinlan K. Sarah Hill: a wild card now speaking up for DCPs. BDJ Team 19 March 2021. Available at: https://www.nature. com/articles/s41407-021-0550-y (accessed May 2021).

https://doi.org/10.1038/s41407-021-0643-7 